\title{
Thyroid screening in pregnancy - a compulsory preventive activity
}

Department of Endocrinology, Faculty of Medicine, “Ovidius” University Constanta

\begin{abstract}
Obiectives: To assess the prevalence of thyroid dysfunction in a group of pregnant women, originating from Dobrogea region of southeastern Romania, considered to be an area without iodine deficiency, including the Black Sea area. Materials and methods: We enrolled 324 pregnant women in different trimesters of pregnancy. Each case was reviewed by a detailed madical history, clinical examination and by serum dosage of thyroid hormones: TSH, FT4, and the antithyroidperoxidase. They were evaluated by comparison with trimester -specific reference range for TSH recommended by American Thyroid Association, then the results were compared with those obtained using the manufacturers reference range. Abortion rate was also analysed. Results: The prevalence of thyroid dysfunction was different in all the 3 trimesters: subclinical hypothyroidism being the most frequently approx. $24 \%$ of all cases; $7 \%$ of pregnant women had overt hypothyroidism. Incidence of thyrotoxicosis in entire study cases was approx. $5.5 \%$. The most frecvent thyroid autoimune disorders were Hashimoto thyroiditis: $42 \%$ - I trimester, $26,6 \%$ in II trimester and about $12,5 \%$ in III-trimester; Graves disease have an incidence of only $0,9 \%(n=3)$. The difference between reference methods eluded a lower number of cases using
\end{abstract}

\section{Eduard Circo}

Fagetului str. 163 bis, 900654, Constanta, Romania, phone: +40241512251 ;

email: eduard_circo@yahoo.com; manufactures reference range for TSH $(\mathrm{P}<0,001)$, but higher for recommended trimester - specific TSH value, confirming the undervalueted hypothesis. The risk of misclassifying the hypothyroidism is between $3 \%-8$ $\%$. Conclusion: Necessity for thyroid hormone dosage periodic/trimesterly/ in pregnancy is a preventive measure. The reference values for hormonal dosage requires trimester-specific assessment. The possibility of hormonal disorders during pregnancy is common. The need for specific therapy at diagnosis depends on the nature of hormonal disorder. Further precautions are needed in pregnant women with known autoimmune thyroid disorder or newly diagnosed.

Keywords: screening, pregnancy, hypothyroidism, thyrotoxicosis, thyroid autoimmunity, abortion

\section{Introduction}

Pregnancy - defines a complex functional unit - feto-placental unit - which possesses its own endocrine activity having a series of maternal adaptive changes required for embryo-fetal development. The factors involved in the genesis of morphological and functional changes of thyroid are endogenous autoimmunity, placental hormones and environmental - iodine intake, contact with goitrous substances. The profile of thyroid function in a "normal" pregnancy comprises : increased serum level of total T4 and T3 (TT4 / TT3), maintaining unchanged the free T4 and 
T3 factions (FT4 and FT3) and normal serum TSH levels. A restrained laboratory diagnosis of thyroid pathology may be due to changing total fractions of T4 and T3 with concomitant increases of serum thyroglobulin $(\mathrm{Tg})$, considered to be adaptive physiological phenomenons. The solution is to assess free T4 and T3 factions as they are only modified in pathological conditions. [1]

Thyroid dysfunction in women of childbearing age is common and untreated may cause a number of undesirable events, especially miscarriage, premature birth and gestational hypertension.[2] Thyroid autoimmunity appears to be associated with a series of complications such as miscarriage or premature birth .[2]

The prevalence of clinically apparent thyroid dysfunction during pregnancy is estimated to be around 1\% [3]. Hyperthyroidism in pregnancy shows a prevalence between $0.1-0,4 \%$, overt hypothyroidism (OH) $0.3 \%-0.5 \%$, while subclinical hypothyroidism $(\mathrm{SCH})$ has a prevalence of $2-3 \%$.[4]

Whilst strong evidence signals that obvious dysfunctions (overt hyper- or hypothyroidism) have harmful effects on pregnancy and fetal development, subclinical dysfunctions, especially subclinical hypothyroidism requires further studies to be confirmed as a risk factor for complications during pregnancy. Moreover, isolated maternal hypothyroxinemia (IMH) is potentially responsible for the psycho-neurological deficit of the descendants. [5]

Therefore, at the moment the indication for thyroxine therapy (LT4) is widely accepted in $\mathrm{OH}$ and the need of therapy in $\mathrm{SCH}, \mathrm{IMH}$ and euthyroid autoimmune thyroid disease remains controversial. [4.6]

Universal maternal prenatal screening is controversial, and there are pros and cons opinions according to cost-effective ratio. The screening is recommended in complete agreement - targeting pregnant women with "high risk" for a thyroid dysfunction being required the presence of at least one of the following criteria: age $>30$ years, family history of hypothyroidism or autoimmune thyroid disease, thyroid autoantibodies (particularly positive TPOAb!), suggestive symptoms of thyroid hypofunction, presence of the goiter, diabetes mellitus type I or other autoimmune diseases, personal history of miscarriage or premature birth, thyroxine substitution treatment, personal history of cervical or cerebral radiation therapy or thyroidectomy, residing in regions with iodine deficiency and women treated for infertility.

European Society of Endocrinology Guidelines [4] doesn't have a consensus, offering two alternatives:

1. Screening for all pregnant women - dosage of TSH in the 9th week of pregnancy or at the first medical check-up.

2. Screening only high-risk pregnant women: identification of pathological TSH in the 9th week of pregnancy or at the first medical check-up.

However identifing cases at risk is not always convenient. Numerous studies showed data confirming that targeted screening may fail to include up to $30 \%$ of the cases with clinical or subclinical hypothyroidism.[8] Avoiding this aspect should be possible by raising awareness and a properly evaluation of all pregnant women regarding the thyroid.

\section{Objectives}

To assess the prevalence of thyroid dysfunction in a group of pregnant women, originating from Dobrogea region of southeastern Romania, considered to be an area without iodine deficiency, including the Black Sea area. The results of this study will determine the usefulness of the screening of all pregnant women concerning the thyroid function.

\section{Material and methods}

We enrolled 324 pregnant women in different trimesters of pregnancy. Each case was reviewed by 
a detailed history, clinical examination and by serum dosage of thyroid hormones: TSH, FT4, and the antiTPOAb (ATPO) using electochemiluminescence immunoassay (ECLIA). Pregnant women in study were checked of personal or family history of thyropathy, presence of autoimmunity, current or previous treatment with levo-thyroxine, antithyroid drugs, surgery or radioiodine therapy. All the cases with a history of thyropathy were excluded from the study. An individualised file was elaborated for each pregnant woman.

The reference values for serum TSH dosage were trimester specific ranges recommended by the ATA (American Thyroid Association) and the laboratory references for FT4.[6] Using these references, the study group was subdivided into 4 subgroups of each trimester.

- Overt hypothyroidism: $\mathrm{TSH}>2,5 \mu \mathrm{IU} / \mathrm{ml}=$ 1st trimester and $>3,0 \mu \mathrm{IU} / \mathrm{ml}$ in the 2 nd and $3 \mathrm{rd}$ trimesters; FT4 $<12.05 \mathrm{pmol} / \mathrm{L}$ in $1 \mathrm{st}$ trimester $;<$ $9.63 \mathrm{pmol} / \mathrm{L}-2$ nd trimester and $<8.39 \mathrm{pmol} / \mathrm{L}-$ 3rd - trimester.

- Subclinical hypothyroidism: TSH> $2.5 \mu \mathrm{IU} /$ $\mathrm{ml}$ in 1 st trimester and $>3,0 \mu \mathrm{IU} / \mathrm{ml}$ in the second and third trimesters FT4 - normal;

- Thyrotoxicosis: TSH $<0,1 \mu \mathrm{IU} / \mathrm{ml}$ for $1 \mathrm{st}$ trimester and $<0.2 \mu \mathrm{IU} / \mathrm{ml}$ in 2 nd trimester and $<0.3$ $\mu \mathrm{IU} / \mathrm{mL}$ and FT4 $>19.6 \mathrm{pmol} / \mathrm{L}$;

- Thyroid normofunction: TSH and FT4 within the limit of reference values.

A subgroup of $\mathrm{SCH}$ pregnant women was also evaluated according to the TSH reference values recommended by the laboratory: TSH: $>4.59 \mu \mathrm{IU} / \mathrm{ml}$ $=1$ st trimester; $>4.10 \mu \mathrm{IU} / \mathrm{ml}=2$ nd trimester and $>$ 3.15 in 3 rd trimester. The results were compared to TSH values recommended by ATA trimester specific ranges.

Statistical analyses: The data gathered was analysed procentualy and for a series of values was determined the statistical significance $(p<0,01)$.

\section{Results}

1. The prevalence of thyroid dysfunction divided by trimesters:

Table I: Maternal thyroid function depending on gestational quarter

\begin{tabular}{|l|c|c|c|c|}
\hline Total, $\mathrm{n}=324$ & $\begin{array}{c}1 \mathrm{st} \\
\text { trimester } \\
(\mathrm{n}=138)\end{array}$ & $\begin{array}{c}2 \mathrm{nd} \\
\text { trimester } \\
(\mathrm{n}=90)\end{array}$ & $\begin{array}{c}\text { 3rd } \\
\text { trimester } \\
(\mathrm{n}=96)\end{array}$ & $\begin{array}{c}\text { Total, } \mathrm{n} \\
(\%)\end{array}$ \\
\hline $\begin{array}{l}\text { Subclinical } \\
\text { hypothyroidism, } \\
\mathrm{n}(\%)\end{array}$ & $43(31,1)$ & $24(26,6)$ & $\begin{array}{c}11 \\
(11,45)\end{array}$ & $78(24)$ \\
\hline $\begin{array}{l}\text { Overt } \\
\text { hypothyroidism, } \\
\mathrm{n}(\%)\end{array}$ & $14(10,1)$ & $7(7,7)$ & $2(2,08)$ & $23(7,09)$ \\
\hline $\begin{array}{l}\text { Thyrotoxicosis, } \\
\mathrm{n}(\%)\end{array}$ & $9(6,5)$ & $7(7,7)$ & $2(2,08)$ & $18(5,5)$ \\
\hline $\begin{array}{l}\text { Thyroid } \\
\text { normofunction, } \\
\mathrm{n}(\%)\end{array}$ & $72(52,1)$ & $52(57,7)$ & $81(84,3)$ & $\begin{array}{c}205 \\
(63,2)\end{array}$ \\
\hline
\end{tabular}

The prevalence of thyroid dysfunction was different in the 3 trimesters: subclinical hypothyroidism being the most frequently approx. $24 \%$ of all cases; $7 \%$ of pregnant women had overt hypothyroidism, while thyrotoxicosis had a prevalence of approx. 5.5\%. (Table I)

The distribution per trimestres reveals the same prevalence of subclinical hypothyroidism prevalence, followed by overt hypothyroidism and thyrotoxicosis.

2. Sublinical hypothyroidism - correlations according to reference range of TSH

Table II Sublinical hypothyroidism correlations according to reference range of TSH

\begin{tabular}{|l|c|c|c|}
\hline TSH values & $\begin{array}{c}\text { I- trimester, } \\
\mathrm{n}=138\end{array}$ & $\begin{array}{c}\text { II- trimester, } \\
\mathrm{n}=90\end{array}$ & $\begin{array}{c}\text { III- } \\
\text { trimester, } \\
\mathrm{n}=96\end{array}$ \\
\hline $\begin{array}{l}\text { Recommended } \\
\text { (ATA) trimester- } \\
\text { specific }\end{array}$ & $43(31,1 \%)$ & $24(26,6 \%)$ & $11(11,45 \%)$ \\
\hline $\begin{array}{l}\text { Recomanded by } \\
\text { manufacturer }\end{array}$ & $32(23,1 \%)$ & $21(23,3 \%)$ & $9(9,3 \%)$ \\
\hline
\end{tabular}


The results of trimester-specific TSH dosage recommended by ATA in subclinical hypothyroidism subgroup of pregnant women were compared to reference values of TSH recomanded by manufacturer.

The difference between reference methods eluded a lower number of cases using manufactures reference range for TSH $(\mathrm{P}<0,001)$, but higher for recommended trimester - specific TSH value, confirming the undervalueted hypothesis. The risk of misclassifying the hypothyroidism is between 3\%$8 \%$.

3. Etiological classification of thyrotoxicosis

Table III: Thyrotoxicosis - etiologic classification:

\begin{tabular}{|l|c|c|c|}
\hline $\begin{array}{l}\text { Total cases }= \\
324\end{array}$ & $\begin{array}{c}1 \mathrm{st} \\
\text { trimester, } \\
\mathrm{n}=9\end{array}$ & $\begin{array}{c}\text { 2nd } \\
\text { trimester, } \\
\mathrm{n}=7\end{array}$ & $\begin{array}{c}\text { 3rd } \\
\text { trimester, } \\
\mathrm{n}=2\end{array}$ \\
\hline $\begin{array}{l}\text { Hyperemesis } \\
\text { gravidarum }\end{array}$ & $7(5,07 \%)$ & - & - \\
\hline Graves Disease & - & $1(0,72 \%)$ & $2(1,44 \%)$ \\
\hline Hashitoxicosis & $2(1,44 \%)$ & $6(4,3 \%)$ & - \\
\hline Total & \multicolumn{3}{|c|}{$18(5,5 \%)$} \\
\hline
\end{tabular}

Etiological classification of thyrotoxicosis reveals the predominance of hyperemesis gravidarum in the 1st trimester followed by hashitoxicosis in the 2nd trimester, Graves' Disease having the lowest incidence of 3 cases in the 2nd and 3rd trimesters. The incidence of hyperthyroidism of all cases was around $3.3 \%$.

4.Thyroid autoimmunity incidence:

Thyroid autoimmunity divided by trimesters was determined by testing the presence of antiTPO-Ab and TRAb (anti TSH receptor), the highest incidence of Hashimoto's thyroiditis being registered in $42 \%$ - in the 1 st trimester, $26.6 \%$ - in 2 nd trimester approx. $12.5 \%$ in the last trimester. Graves' disease was present in only 3 cases $(0.9 \%)$ of all cases.
Table IV. Incidence of autoimmune thyroid disease divided by trimesters.

\begin{tabular}{|l|l|l|l|l|}
\hline & $\begin{array}{l}\text { 1st } \\
\text { trimester, } \\
\mathrm{n}=138\end{array}$ & $\begin{array}{l}\text { 2nd } \\
\text { trimester, } \\
\mathrm{n}=90\end{array}$ & $\begin{array}{l}\text { 3rd } \\
\text { trimester, } \\
\mathrm{n}=96\end{array}$ & Total \\
\hline $\begin{array}{l}\text { Graves' } \\
\text { Disease }\end{array}$ & - & $\begin{array}{l}1 \\
(1,1 \%)\end{array}$ & $\begin{array}{l}2 \\
(2,08 \%)\end{array}$ & $30,92 \%)$ \\
\hline $\begin{array}{l}\text { Chronic } \\
\text { autoimmune } \\
\text { thyroiditis } \\
(\text { anti- } \\
\text { TPOAb+) }\end{array}$ & $\begin{array}{l}58 \\
(42 \%)\end{array}$ & $\begin{array}{l}24 \\
(26,6 \%)\end{array}$ & $\begin{array}{l}12 \\
(12,5 \%)\end{array}$ & $\begin{array}{l}94 \\
(29,01 \%)\end{array}$ \\
\hline
\end{tabular}

\section{Rate of abortion}

Case analysis of abortion reveals a total of 14 cases in which the pregnancy was interrupted during the first trimester without associating thyroid disorder; only 4 cases of abortion in study group were due to thyroid dysfunction.

Table V: Incidence of abortions in the study group

\begin{tabular}{|l|c|}
\hline Number of cases $=324$ & $14(10.1 \%)$ \\
\hline $\begin{array}{l}\text { First trimester abortion } \\
\text { without thyroid hormonal } \\
\text { disorders }\end{array}$ & $2(1,07 \%)$ \\
\hline Graves' Disease & $2(2,08 \%)$ \\
\hline $\begin{array}{l}\text { Last trimester } \\
\text { hypothyroidism }\end{array}$ & \\
\hline
\end{tabular}

\section{Discutions}

The present study followed the prevalence of thyroid disfunction in pregnant women of different gestational period, using recommended trimesterspecfic reference value for TSH and manufacture range for FT4. The prevalence for clinical manifested hypothyroidism and subclinical hypothyiroidism were higher than those mentioned in speciality literatures.[3,4] This difference between studies may be due to inclusion of women of different ethnicities, 
from different georgraphical areas and to the different reference value for TSH.

High incidence of chronic autoimmune thyroiditis (positive TPOAb) in almost 29\% comparative with previous studies[9] may be explained by increase of autoimune thyroid desease in our georgafical area, knowing to be an iodine sufficient region.

Pregnant women with low values of TSH (with high or normal FT4) were identified in 5,5\% \% from total of cases. Hyperthyroidsm incidence in this study has been comparabile with results from other studies - 2,6- $5 \%$.[8].

Assessment of thyroid dysfunction implies well established hormonal reference range.We compared the incidence of subclinical hypothyroidism using trimester -specific reference range for TSH recommended by ATA, then the results were compared with those obtained using the manufactures reference range. The number of pathological findings were lower in appreciation using manufactures reference range. The risk of missing an important number of pathological cases is about $8 \%$, a harmful and useless aspect as far as the thyroxine treatment doesn't represent a risk only by its absence. Other studies confirm the fact that testing only high-risk pregnant women may lead to about $10,6-30 \%$ of undiagnosed hypothyroidism. $[4,6,8]$ The heterogeneity of the results obtained in these studies attests features of expression at a populational level and the possible involvement of potentially goitrous environmental factors.

The presence of autoimmunity and thyroid hypofunction in the first trimester of pregnancy increases the risk of thyroid disfunction and a 6- fold increased risk of developing diabetes mellitus in pregnancy.[9]

Untreated maternal hypothyroidism is associated with neonatal and obstetrical complications, although less common found in subclinical hypothyroidism.[10,11]

Thyroxine replacement therapy certainly offers a benefit by reducing the risk of maternal and fetal complications. International guidelines recommendations for thyroxine substitution in pregnant women with positive ATPO and subclinical hypothyroidism [6] confirmed the results of this study.

\section{Conclusions:}

Necesity for thyroid hormone dosage periodic / trimesterly/ in pregnancy is a preventive measure.

The reference values for hormonal dosage require trimester-specific assessment.

The possibility of hormonal disorders during pregnancy is common.

The need for specific therapy after diagnosis depends on the nature of hormonal disorder.

Further precaution measures are needed in pregnant women with known autoimmune thyroid disorder or newly diagnosed.

\section{Acknowledgements}

" This work received financial support through the project entitled "CERO - Career profile: Romanian Researcher", grant number POSDRU/159/1.5/S/135760, cofinanced by the European Social Fund for Sectoral Operational Programme Human Resources Development 20072013”.

\section{References}

1. Circo, E. (2001). Boli endocrine - intalnite in sarcina si postpartum. Medical Update. VII (5), 327-239.

2. Negro, R. \& Mestman, J.H. (2011). Thyroid disease in pregnancy. Best practice \& research: clinical endocrinology \& metabolism. 25(6), 927-943. doi:10.1016/j.beem.2011.07.010.

3. Lazarus, J.H. \& Premawardhana, L.D. (2005). Screening for thyroid disease in pregnancy. 
$J$ Clin Pathol. 58(5), 49-52. doi:10.1136/ jcp.2004.021881.

4. De Groot, L., Abalovich, M. \& Alexander, E.( 2013). Management of Thyroid Dysfunction during Pregnancy and Postpartum: An Endocrine Society Clinical Practice Guideline. The Journal of Clinical Endocrinology \& Metabolism. 97(8), 2543-65 doi: 10.1210/jc.2011-2803.

5. Pop, V., Brouwers, E.P, \& Vader, H.L. (2003). Maternal hypothyroxinaemia during early pregnancy and subsequent child development: a 3-year follow-up study. Clinical Endocrinology 59, 282-288.

6. Stagnaro-Green, A. \& Abalovich, M. (2011). Guidelines of the American Thyroid Association for the Diagnosis and Management of Thyroid Disease During Pregnancy and Postpartum. Thyroid. 21(10), 1081-1125. DOI: 10.1089/ thy.2011.0087
7. Henry, J.B. (1998). Evaluation of endocrine function .In clinical diagnosis and management by Laboratory Methods. ASM Press, USA, 20 ed, 310-311.

8. Altomare, M. \& La Vignera, S. (2013). High prevalence of thyroid dysfunction in pregnant women. J Endocrinol Invest. 36(6). pg.407-411. DOI: $10.3275 / 8658$

9. Männistö, T., Vääräsmäki, M. \& Pouta,A.(2010). Thyroid Dysfunction and Autoantibodies during Pregnancy as Predictive Factors of Pregnancy Complications and Maternal Morbidity in Later Life. The Journal of Clinical Endocrinology \& Metabolism. 95(3), 1084-94. DOI: 10.1210/ jc.2009-1904 